\title{
The construction and use of bacterial DNA microarrays based on an optimized two-stage PCR strategy
}

Bradley L Postier ${ }^{1}$, Hong-Liang Wang ${ }^{1}$, Abhay Singh ${ }^{2}$, Lori Impson ${ }^{1}$, Heather L Andrews ${ }^{1}$, Jessica Klahn ${ }^{1}$, Hong Li² ${ }^{2}$ George Risinger ${ }^{1}$, David Pesta ${ }^{1}$, Michael Deyholos ${ }^{3}$, David W Galbraith ${ }^{3}$, Louis A Sherman ${ }^{2}$ and Robert L Burnap*1

Address: ${ }^{1}$ Department of Microbiology \& Molecular Genetics, Oklahoma State University, Stillwater, OK 74078 USA, ${ }^{2}$ Department of Biological Sciences, Purdue University, West Lafayette, IN 47907-1392, USA and ${ }^{3}$ Department of Plant Sciences, University of Arizona, Tucson AZ 85721 USA

Email: Bradley L Postier - postier@biochem.okstate.edu; Hong-Liang Wang - hlwang31@hotmail.com; Abhay Singh - singh1@purdue.edu; Lori Impson - impson@biochem.okstate.edu; Heather L Andrews - heatherandrews7@ hotmail.com; Jessica Klahn - jessibear77@ hotmail.com; Hong Li - hli@bilbo.bio.purdue.edu; George Risinger - risingg78@ hotmail.com; David Pesta - davidpesta@hotmail.com;

Michael Deyholos - deyholos@ualberta.ca; David W Galbraith - galbraith@arizona.edu; Louis A Sherman - lsherman@bilbo.bio.purdue.edu; Robert L Burnap* - Burnap@biochem.okstate.edu

* Corresponding author

Published: 12 June 2003

Received: 4 March 2003

BMC Genomics 2003, 4:23

Accepted: 12 June 2003

This article is available from: http://www.biomedcentral.com//47I-2/64/4/23

(c) 2003 Postier et al; licensee BioMed Central Ltd. This is an Open Access article: verbatim copying and redistribution of this article are permitted in all media for any purpose, provided this notice is preserved along with the article's original URL.

\begin{abstract}
Background: DNA microarrays are a powerful tool with important applications such as global gene expression profiling. Construction of bacterial DNA microarrays from genomic sequence data using a two-stage PCR amplification approach for the production of arrayed DNA is attractive because it allows, in principal, the continued re-amplification of DNA fragments and facilitates further utilization of the DNA fragments for additional uses (e.g. over-expression of protein). We describe the successful construction and use of DNA microarrays by the two-stage amplification approach and discuss the technical challenges that were met and resolved during the project.
\end{abstract}

Results: Chimeric primers that contained both gene-specific and shared, universal sequence allowed the two-stage amplification of the 3,168 genes identified on the genome of Synechocystis sp. PCC6803, an important prokaryotic model organism for the study of oxygenic photosynthesis. The gene-specific component of the primer was of variable length to maintain uniform annealing temperatures during the Ist round of PCR synthesis, and situated to preserve full-length ORFs. Genes were truncated at $2 \mathrm{~kb}$ for efficient amplification, so that about $92 \%$ of the PCR fragments were full-length genes. The two-stage amplification had the additional advantage of normalizing the yield of PCR products and this improved the uniformity of DNA features robotically deposited onto the microarray surface. We also describe the techniques utilized to optimize hybridization conditions and signal-to-noise ratio of the transcription profile. The inter-lab transportability was demonstrated by the virtual error-free amplification of the entire genome complement of 3,168 genes using the universal primers in partner labs. The printed slides have been successfully used to identify differentially expressed genes in response to a number of environmental conditions, including salt stress.

Conclusions: The technique detailed here minimizes the cost and effort to replicate a PCRgenerated DNA gene fragment library and facilitates several downstream processes (e.g. directional cloning of fragments and gene expression as affinity-tagged fusion proteins) beyond the primary objective of producing DNA microarrays for global gene expression profiling. 


\section{Background}

DNA microarrays have proven to be a particularly effective tool for genome-wide transcript profiling, and they can generate information on the accumulation and disappearance of thousands of specific transcripts in a single experiment [1-5]. Because such an array generates vast quantities of data, it is desirable to improve the statistical reliability of the data through experimental repetitions. Additionally, it is useful to perform time course experiments involving multiple time points to enable the application of cluster analysis to classify groups of genes exhibiting similar temporal patterns of regulation in response to shifts in environmental conditions. Therefore, a robust experimental design may involve the consumption of many individual DNA microarrays. Given these considerations, it is important to have methods for improving the efficiency and economy of microarray production.

Since the bacterial genes are typically not cloned at a genome-wide scale as non-redundant, ordered sets, as with eukaryotic cDNA libraries, it is not possible to use 'universal primers' (e.g. T3, T7 sequences) and therefore PCR amplification requires design and synthesis of PCR primers for all target genes. In this context, the construction of bacterial DNA microarrays from genomic sequence data using a 'two-stage' approach, is attractive because it allows the continued re-amplification of DNA fragments and facilitates further utilization of the DNA fragments for additional uses (e.g. over-expression of protein) [6]. This approach involves the use of chimeric primers containing both gene-specific and engineered sequences (adaptamers). These primers are used to synthesize PCR products directly from genomic DNA, which serves as template during the first stage of PCR amplification. This amplification can be performed for thousands of genes during a given production run using well-established procedures that include microtiter plates and multichannel pipetting techniques to afford efficient parallel processing of the samples. The products of this first stage of amplification are gene sequences flanked by the arbitrary adaptamer sequences engineered into the first stage PCR primers. The adaptamer sequences become the basis for re-amplification of the gene sequences in a second stage amplification. During the second stage of amplification, the first stage PCR products serve as template, whereas a single pair of primers recognizing the flanking adaptamer sequence can be used to re-amplify all products of the first stage PCR.

In this report, we describe the procedures for the production and use of DNA microarrays for the cyanobacterium Synechocystis PCC6803. This organism is a widely used experimental model for the study of gene expression and plant-like oxygenic photosynthesis [7]. Synechocystis
PCC6803 was predicted to contain 3,168 open reading frames (prior to May 2002) http://www.kazusa.or.jp/ cyano/index.html[8]. Of these, over 50\% (>1700 ORFs) have been characterized as hypothetical or having no similarity to known sequences. Thus, differential gene expression via microarray analysis will represent an important functional genomics approach and we describe the twostage PCR strategy that led to the successful production of full-genome microarray for Synechocystis .

\section{Methods}

\section{Growth conditions and RNA isolation}

Synechocystis PCC6803 cultures were grown autotrophically in BG-11 medium essentially as described by Williams [9]. Specifically, $500 \mathrm{~mL}$ cultures were grown in flat ( $4 \mathrm{~cm}$ across the light path) Bellco tissue culture flasks at $30^{\circ} \mathrm{C}$ under white light fluorescent illumination (Cool White ${ }^{\circledast}$, General Electric) with an incident intensity of 80 $\mu$ moles photons $\mathrm{m}^{-2} \mathrm{~s}^{-1}$. Aeration was provided by bubbling with air enriched with $3 \% \mathrm{CO}_{2}$ at a rate of $300 \mathrm{~mL}$ $\mathrm{min}^{-1}$. RNA was isolated using hot phenol conjunction with vigorous agitation with glass beads as described by Bhaya et al. [10].

\section{Chimeric oligonucleotide design and PCR amplification}

Figure 1 provides a flow chart of the preparation of the full-genome Synechocystis microarray. Oligonucleotides, synthesized by Sigma Genosys http://www.sigmagenosys.com/, were designed to amplify the complete coding region of each open reading frame from the sequenced genome of Synechocystis PCC6803. The only exceptions were instances for genes with a predicted length extending beyond $2 \mathrm{~kb}$. Of the 3,168 open reading frames, fewer than $10 \%$ (261) of the genes were truncated at the 3 '-end to the $2 \mathrm{~kb}$ limit. Each of the oligos is a chimeric sequence designed for first round synthesis and, as such, contained two components: a 5' universal sequence and a 3 ' genespecific sequence as shown in Figure 2. The gene-specific region of the oligonucleotides begins at the first or last base of the open reading frame and continues inside until the $\mathrm{T}_{\mathrm{m}}$ of the oligo was in the range of $58-62^{\circ} \mathrm{C}(25-45$ $\mathrm{nt}$, including the universal sequence). An algorithm (Sigma Genosys) based upon Primer3 (Whitehead Institute) was used for this purpose and resulted in a high frequency of successful amplification as discussed below. Importantly, the universal sequences were designed to include SapI restriction sites in order to facilitate downstream applications, including cloning into an expression vector. Aliquots of the oligonucleotides were transferred and mixed as primer pairs to separate locations of 96-well plates prior to delivery from the commercial source, which facilitated amplification in the 96-well format. The remaining products from the synthesis reaction were stored in individual tubes at $-20^{\circ} \mathrm{C}$. 


\section{Preparation of a Full-genome Microarray in the Cyanobacterium Synechocystis sp. PCC 6803}
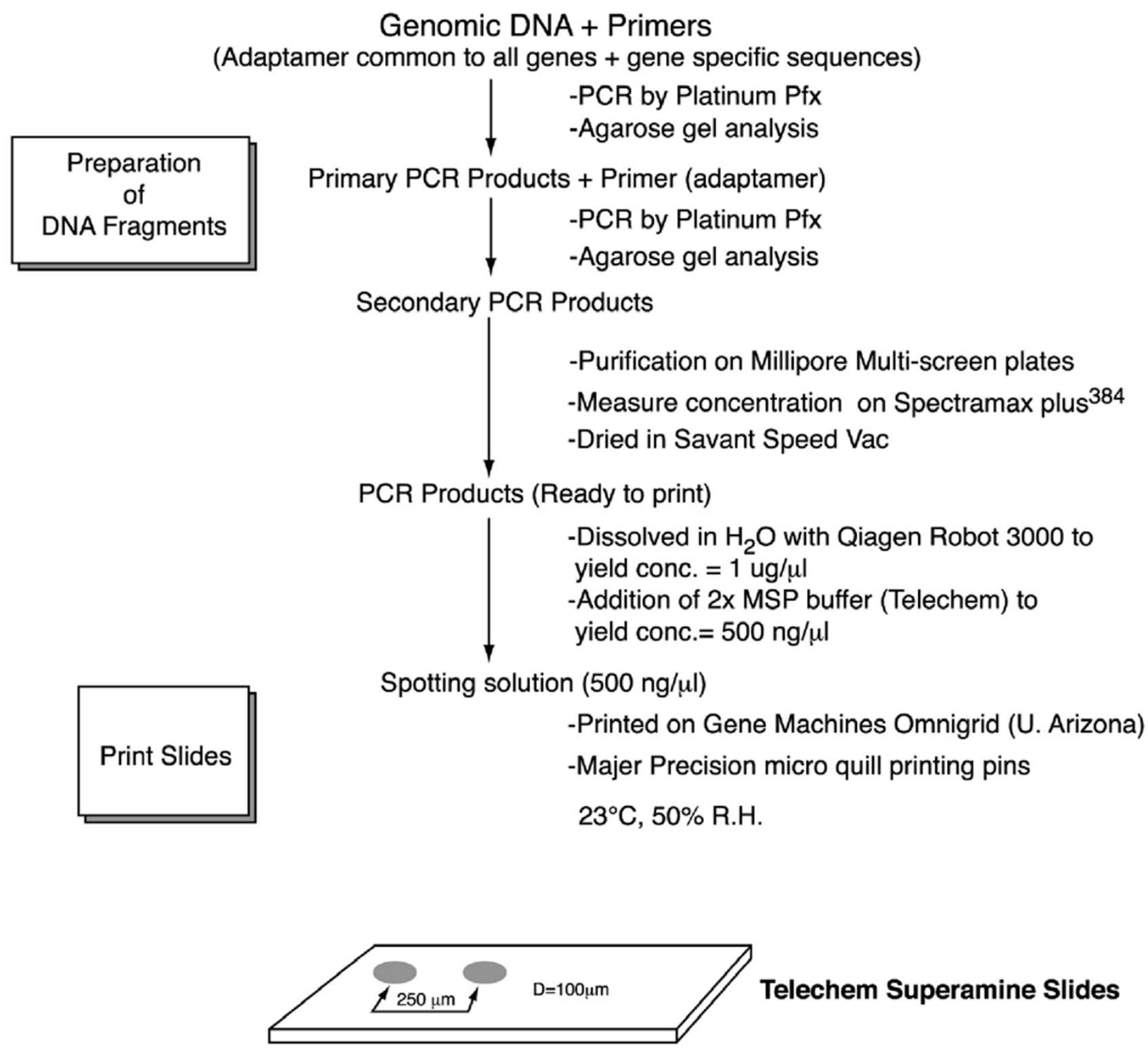

Each gene printed in triplicate

Figure I

Overall strategy for the production of bacterial DNA microarrays using the two-stage PCR approach for the production DNA microarray elements. 


\section{Amplification Strategy}
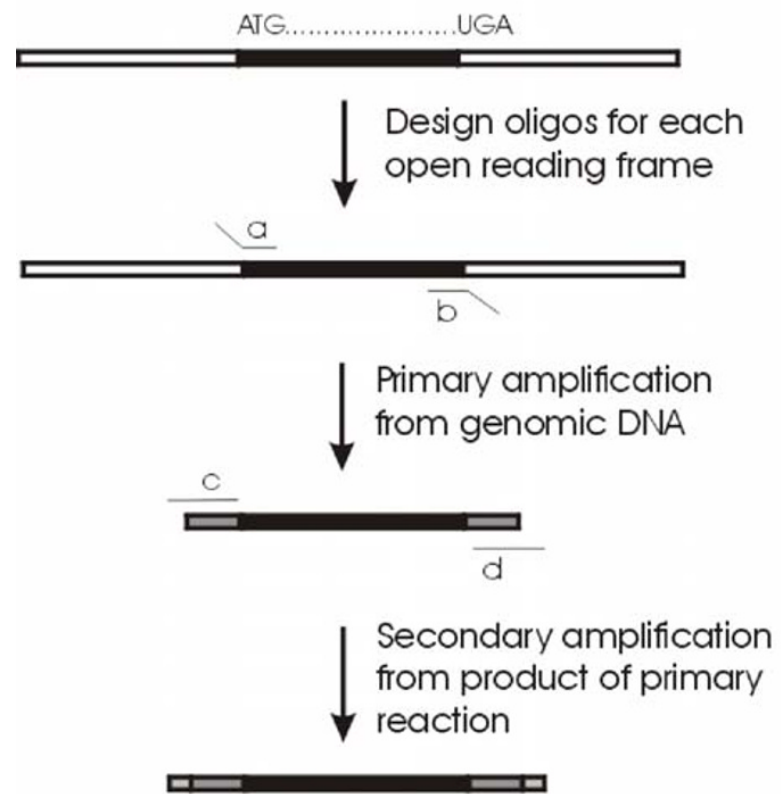

Analyze, purify, and print

\section{Chimeric oligo sequences: \\ $a=5$ ' GGAGCTCTTCC/ATGNNN...(?) 3' \\ b=5' GGT}

\section{Universal oligo sequences: c=5' CCAGGGGAGCTCTTCC/ATG3' $\mathrm{d}=5$ ' GCACGGGT GCTCTTCC/ACC3'}

\section{Figure 2}

Design and use of chimeric bipartite oligonucleotides for PCR amplification of each open reading frame of the genome from Synechocystis PCC6803. Bipartite oligos ( $a$ and $b$ ) were designed to include: I) a gene specific sequence at their $3^{\prime}$ end of variable length to maintain a constant $t_{m}$ of $58-62^{\circ} \mathrm{C}$; and 2 ) universal sequence at their $5^{\prime}$ to introduce a common sequence to all primary products. These primary products were then re-amplified by universal oligonucleotides (c and d) introducing more universal sequence. The re-amplification of products using universal oligonucleotides allows amplification of all products under optimized conditions, thus improving the success rate and product yields. The final products of the second amplification are analyzed for size, yield, and lack of multiplicity on agarose gels, then purified, resuspended in printing buffer, and printed on modified surface glass slides. This strategy minimizes the cost and effort to replicate the PCR-generated DNA gene fragment library and facilitates several downstream processes beyond the primary objective of producing DNA microarrays.
First round amplifications were performed in 96-well microtiter dish format using PTC-100 Thermocyclers from MJ Research Inc. Five $\mu \bullet$ of $20 \mu \mathrm{M}$ premixed primer pairs were transferred to $0.2 \mathrm{ml}$ Thermo-Fast ${ }^{\circledast}$ 96-well plates (Marsh cat. No. AB-0600) and mixed with $95 \mu$ l of Reaction mix 1 (For 110 reactions; $55 \mu \mathrm{l} \mathrm{of} 500 \mu \mathrm{g} / \mathrm{ml}$ chromosomal DNA, $1.1 \mathrm{ml} \mathrm{Pfx}$ Buffer $^{\circledast}, 1.1 \mathrm{ml}$ Pfx Enhancer reagent $^{\circledast}, 220 \mu \mathrm{l} 50 \mathrm{mM} \mathrm{MgSO}_{4}, 165 \mu \mathrm{l} 10 \mathrm{mM}$ premixed dNTPs [Amersham Pharmacia cat. No. 93-77212], $88 \mu \mathrm{l}$

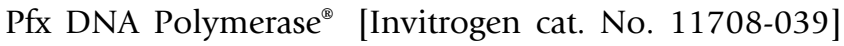
and $7.722 \mathrm{ml}$ sterile, deionized water). Plates were sealed using Microseal ${ }^{\mathrm{TM}}$ 'A' film (MJ Research cat. No. MSA50001) during thermal cycling. Step-down thermocycling conditions consisted of $2 \mathrm{~min} 94^{\circ} \mathrm{C}$ initial denaturation followed by ten rounds of $94^{\circ} \mathrm{C}$ for $30 \mathrm{~s}, 62^{\circ} \mathrm{C}$ ($1^{\circ} \mathrm{C} /$ cycle) for $45 \mathrm{~s}$, and $68^{\circ} \mathrm{C}$ for $3 \mathrm{~min}$. The step down cycling was followed immediately by 24 cycles of $94^{\circ} \mathrm{C}$ for $30 \mathrm{~s}, 52^{\circ} \mathrm{C}$ for $45 \mathrm{~s}$ and $68^{\circ} \mathrm{C}$ for $3 \mathrm{~min}$. Five $\mu \mathrm{l}$ of each sample was mixed with an equal volume of $20 \%$ glycerol and loaded on $0.7 \%$ agarose/TAE gels stained with ethidium bromide and separated by electrophoresis in Bio-Rad Sub-cell ${ }^{\circledast}$ model 192 units. Gels were analyzed using an Alpha Imager ${ }^{\mathrm{TM}} 2000$ workstation and software for image capture and Total Lab v. 1.10 (Phoretix) software for image analysis. Second round products were generated with universal primers and products of the first round of amplification. Specifically, $5 \mu \mathrm{l}$ of the original $100 \mu \mathrm{l}$ reaction was transferred to new plates and mixed with $95 \mu \mathrm{l}$ reaction mix 2 (For 110 reactions; $1.1 \mathrm{ml} 10 \mathrm{X}$ Buffer, 220 $\mu \mathrm{l} 50 \mathrm{mM} \mathrm{MgSO}_{4}, 165 \mu \mathrm{l}$ premixed $10 \mathrm{mM}$ dNTP's, 550 $\mu \mathrm{l} 20 \mu \mathrm{M}$ universal primer pair, $1.1 \mathrm{ml} \mathrm{Pfx}$ Enhancer reagent, $88 \mu \mathrm{l}$ Pfx enzyme, and $7.227 \mathrm{ml}$ sterile, deionized water). Amplifications were carried out by denaturation for $2 \mathrm{~min}$ at $94^{\circ} \mathrm{C}$ followed by 35 cycles of the following conditions: $94^{\circ} \mathrm{C}$ for $15 \mathrm{~s}, 55^{\circ} \mathrm{C}$ for $45 \mathrm{~s}$, and $68^{\circ} \mathrm{C}$ for 2 min. After completion of all 35 cycles, an additional extension period at $68^{\circ} \mathrm{C}$ for $20 \mathrm{~min}$ was added to polish the ends. Five $\mu \mathrm{l}$ of each sample was loaded into $0.7 \%$ agarose gels and analyzed as described above. Oligonucleotides for unsuccessful products after the second round reaction were redesigned, resynthesized, and used for reamplification. PCR fragments were compared to a known size marker (Cat. No. 10068-013, Invitrogen). Products were scored successful if their length, as defined by gel analysis, was $+/-15 \%$ of their predicted length, contained only a single band, and were of adequate density.

\section{Purification, preparation, and printing DNAs}

Upon verification of successful amplification by gel analysis, each plate of second round PCR products was purified using Multiscreen-PCR plates from Millipore according to the manufacturers specifications, except that a pre-wash was incorporated to remove potential surfactant type agents present in at least some batches of the filtration units. The resulting products were resuspended 
in $50 \mu$ sterile deionized water at room temperature on a rotary shaker for 30 minutes. The yield of each product was measured by calculating concentration from $\mathrm{A}_{260}$ values using Corning Incorporated's Costar UV transparent 96 well plates with the Molecular Devices Spectramax 384 Plus spectrophotometer. The products were then dried in a Savant DNA110 Speed Vac. Using a Qiagen Bio-Robot $3000^{\mathrm{TM}}$, each product was resuspended in water to 1.0 $\mu \mathrm{g} . \mu \mathrm{l}^{-1}$. To each sample, an equal volume of $2 \mathrm{X}$ Microspotting solution (Cat. No. MSS-1, Telechem) was added. Ten microliter of each product was transferred to two sets of 384 Micro Array plates (Cat. No. X7020, Genetix Limited). Using a Omnigrid arrayer (Gene Machines) and 16 Microquill 2000 pins (Majer Precision), arrays were printed in triplicate on Superamine slides (cat. No. SMM25, Telechem), using 250 micron spacing, in $18 \times 15$ spot subgrids. To improve spot morphology, blotting was increased to 30 spots per dip, and pins were re-dipped into the sample after every 50 slides. Cross-contamination between successively spotted samples is a potentially severe problem and was found to be minimized by increasing the stringency of pin washing procedures beyond the manufacturer's recommendations by increasing sonication in the washing solution for 5 seconds at the highest power setting. Relative humidity was maintained at $50 \%$ and temperature at $23^{\circ} \mathrm{C}$ throughout the arraying procedure.

\section{Array process verification}

At the end of printing, one or two slides were used to verify the quality of printing such as spot morphology and intensity. Slides were baked at $80^{\circ} \mathrm{C}$ for one hour, washed with $0.1 \%$ SDS and rinsed in deionized water. The slide was then stained with 100 nanomole aqueous Syto-61 (Molecular Probes) solution, washed twice with $0.1 \%$ SDS, rinsed once in deionized water and scanned for fluorescence at $550 \mathrm{~nm}$ in the ScanArray 3000. Each wash or rinse was carried out at room temperature for 5 minutes. The scanned images were analyzed for spot morphology and intensity and the results of the analysis were used to optimize the printing process during each run.

\section{Labeled cDNA production}

Fluorescently labeled cDNA was produced using a twostep procedure involving cDNA production from target RNA using a reverse transcriptase reaction incorporating aminoallyl-modified deoxynucleotide (aadUTP), followed by the second step involving chemical coupling of fluorescent dye (either $\mathrm{Cy} 3$ or Cy5) to the introduced amino moieties of the newly synthesized cDNA. The cDNA was synthesized from $16 \mu \mathrm{g}$ total RNA using $5 \mu \mathrm{g}$ random 8-base oligonucleotides (Sigma GenoSys) and Superscript II $^{\mathrm{TM}}$ reverse transcriptase (Invitrogen). RNA samples (control and experimental) were each mixed with random octamers in a total volume of $25 \mu \mathrm{l}$ DEPC (diethylpyrocarbonate) treated water, heated to $65^{\circ} \mathrm{C}$ for 5 minutes and then transferred to $42^{\circ} \mathrm{C}$. Subsequently, 25 $\mu \mathrm{l}$ of a premix containing $2 \mu \mathrm{l}$ of $100 \mathrm{mM}$ DTT (dithiothreitol), $10 \mu \mathrm{l} 5 \mathrm{X}$ Superscript II buffer, $1 \mu \mathrm{l}$ 50X aadNTP $\operatorname{mix}(25 \mathrm{mM} \mathrm{dA}, \mathrm{C}$, and GTP, $8.4 \mathrm{mM}$ dTTP, and $16.6 \mathrm{mM}$ aadUTP [Sigma Cat. No.A-5660]), $10 \mu \mathrm{l}$ DEPC treated water, and $2 \mu \mathrm{l}$ Superscript II was added to each tube. Following two hour incubation at $42^{\circ} \mathrm{C}, 4 \mu \mathrm{l} 50 \mathrm{mM}$ EDTA and $2 \mu \mathrm{l} 10 \mathrm{~N} \mathrm{NaOH}$ was added to each tube and incubated at $65^{\circ} \mathrm{C}$ for 20 minutes to degrade RNA. The reaction was neutralized by the addition of $4 \mu \mathrm{l} 5 \mathrm{M}$ acetic acid. The cDNA was purified using Millipore Microcon 30 centrifugal filter devices by diluting the reaction mix with sterile deionized water to a volume of $500 \mu \mathrm{l}$ according to the manufacturers specifications. Each of the two samples was washed five times using $500 \mu$ l deionized water and the final retentate adjusted to approximately $50 \mu \mathrm{l}$ to facilitate handling. The resultant solutions were dried at room temperature in the Speed Vac, and the pellets were resuspended in $20 \mu \mathrm{l} 0.1 \mathrm{M} \mathrm{Na}_{2} \mathrm{CO}_{3}$ ( $\mathrm{pH}$ 9.0) and mixed with $10 \mu$ of previously prepared Cy3 or Cy 5 dye. Preparation of the dyes was performed in advance and involved dissolving one tube of powdered Cy3 or Cy5 dye from Amersham Pharmacia Biotech Cat. No. PA23001, or PA 25001 respectively, in $55 \mu \mathrm{l}$ dimethyl sulfoxide and storing at $20^{\circ} \mathrm{C}$ until use. The coupling reaction was carried out at room temperature in the dark for 1 hour. The reaction was quenched by the addition of $4.5 \mu \mathrm{l} 4 \mathrm{M}$ hydroxylamine, followed by incubation for an additional $5 \mathrm{~min}$. The Cy3or Cy5 dye-coupled cDNA samples were combined and purified using a Qiagen PCR product purification kit according to the manufacturer's specifications. Samples were adjusted to $14.75 \mu \mathrm{l}$ using SpeedVac and remainder of the hybridization components containing $2.5 \mu \mathrm{l}$ of 10 $\mu \mathrm{g} / \mu \mathrm{l}$ salmon sperm DNA, $8.75 \mu \mathrm{l} 20 \mathrm{X}$ SSC, $0.25 \mu \mathrm{l} 10 \%$ SDS, and $8.75 \mu$ l formamide were added. The mixture was then heated for 2 minutes at $99^{\circ} \mathrm{C}$, briefly centrifuged at high speed, and maintained at $42^{\circ} \mathrm{C}$ until the hybridization with the DNA microarray was begun.

\section{Hybridization and wash conditions}

Printed slides were baked at $80^{\circ} \mathrm{C}$ for 1 hour, washed twice for 2 minutes each at room temperature in $0.1 \%$ SDS and once in deionized water to remove unbound material. The slides were boiled in deionized water for 3 minutes to denature the printed DNA, dried using low speed centrifugation in a specialized microscope slideaccommodating rotor (Telechem). The DNA on the microarray was then subjected to a UV-cross-linking at a dose of $150 \mathrm{~mJ} / \mathrm{cm}^{2}$. Prehybridization was performed by incubating the slide in a fresh mixture of $100 \mathrm{ml}$ of $25 \%$ formamide, 5X SSC, $0.1 \%$ SDS, and 1\% BSA for $45 \mathrm{~min}$. at $42^{\circ} \mathrm{C}$ in a Coplin jar. The slide was then rinsed under distilled water and dried using low speed centrifugation. 


\title{
Table I: Construction of DNA microarray
}

\begin{abstract}
Microarrays are constructed by synthesizing oligonucleotides on glass slides, by spotting PCR-amplified cDNA clones from EST data (eukaryotes), or by spotting PCR products from genomic DNA template (prokaryotes) using a set of gene-specific primers. The method described in this paper has the advantage of being both more cost effective and less labor intensive for the construction of microarrays from prokaryotic organisms. The procedure is most useful for those laboratories working with organisms for which commercial microarrays are unavailable. The salient features of our approach include:

- Bipartite Primer: The use of a bipartite primer for the amplification of genes has several advantages (see text). Importantly, it permits the use of a common primer for the amplification of all genes in the second and subsequent amplification steps. This simple modification in primers alleviates the problem of primer-limitation and therefore, is particularly valuable in constructing many arrays for a multi-investigative, collaborative effort.

- Two stage amplification: The use of the two-stage amplification process increases the signal-to-noise ratio by diminishing the hybridization signal resulting from contaminating genomic DNA used for amplification of PCR fragments. Additionally, it also yields relatively uniform quantities of PCR products.

- Purification and Quantitation: For efficient binding of the amplified products and to reduce the background signal, it is essential to purify the products. We found ethanol precipitation unsatisfactory, whereas the use of Multiscreen filter plates gave excellent results. One drawback with this technique is the relatively lower percentage recovery of smaller fragments. Therefore, following purification, fragments were quantified and normalized to an equal concentration.

- Printing: We checked the suitability of various slide surfaces (poly-Lysine and amine) and the spotting buffers from a number of commercial vendors to ensure reproducible and uniform spot morphology and maximal retention of DNA. We found that Superamine slides and MSP spotting buffer from Telechem gave satisfactory results.
\end{abstract}

The slide was preheated at $42^{\circ} \mathrm{C}$ in a Telechem hybridization chamber by placing in a static $42{ }^{\circ} \mathrm{C}$ incubator. The pre-warmed sample was pipetted and spread uniformly onto a $24 \times 60 \mathrm{~mm}$ glass cover-slip (Fisher Scientific, Cat. No., 12-548-5P) and the pre-warmed slide was inverted and placed with the arrayed surface contacting the sample on the cover-slip surface. Deionized water $(10 \mu \mathrm{l})$ was added to each of the reservoirs of a Telechem Hybridization Chamber, and the slide was transferred to and enclosed within the chamber. The slide was incubated in a static incubator at $42^{\circ} \mathrm{C}$ for $12-16 \mathrm{~h}$, and washed by placing in a $250 \mathrm{ml}$ solution of $2 \mathrm{X}$ SSC and $0.1 \%$ SDS at $42^{\circ} \mathrm{C}$ for 5 minutes with gentle agitation provided by rotation of a magnetic stir bar. The slide was transferred quickly to a solution of $0.1 \mathrm{X}$ SSC, and $0.1 \%$ SDS, incubated for 10 minutes at room temperature with gentle agitation, and washed 5 additional times in 0.1X SSC for 1 min. at room temperature. The slide was then rinsed briefly with deionized water and dried by low speed centrifugation. The slides were stored in the dark until scanned.

\section{Results and Discussion}

The goal of this project was to develop a DNA microarray as part of an overall strategy for functional genomics in the unicellular model cyanobacterium, Synechocystis PCC6803. The two-stage amplification strategy (6) was adopted as a means to facilitate replication of the arrays as needs dictated (Figure 1). In general terms, the optimization of this technical approach required particular attention to the design of the adaptamers, the choice and use of the thermostable DNA polymerase, and the thermocycling conditions. Other technical factors, such as the array printing conditions, were found to conform to observa- tions that are well-described in the literature. Overall, the rate-limiting production steps following the reaction optimization were those involving the analysis of the products. Figure 1 outlines the main features of this successful construction project and Table 1 highlights some of the key parameters that we tested during the array construction.

Critical design features of the chimeric first round primers were the inclusion of the directional cloning and expression features, plus the inclusion of a good common template sequence for the subsequent second round amplification. The adaptamers included the introduction of $\mathrm{G}+\mathrm{C}$ rich sequences at the 5 ' termini to stabilize the end structure of the first round PCR products. Another important design aspect that proved critical, according to our preliminary tests, was incorporation of an additional five base $\mathrm{G}+\mathrm{C}$ rich overhang in the universal primers used for the second round PCR (Figure 2). The absence of the additional sequences resulted in very poor PCR performance compared to the excellent performance observed with their inclusion.

Importantly, the two-stage amplification had the unanticipated advantage of normalizing the yield of PCR products across the entire set of genes, such that lower than average yielding products from the $1^{\text {st }}$ round PCR (using the gene specific sequence and chromosomal DNA as template) often had a robust yield during the $2^{\text {nd }}$ round of amplification using the common adaptamer sequences. Although the primers were deliberately designed in such a way that oligo $\mathrm{T}_{\mathrm{m}}$ 's fell in narrow range, it was determined after a number of trials that it was necessary to use 'touchdown' PCR conditions for the first round amplifica- 
A

Primary Amplification

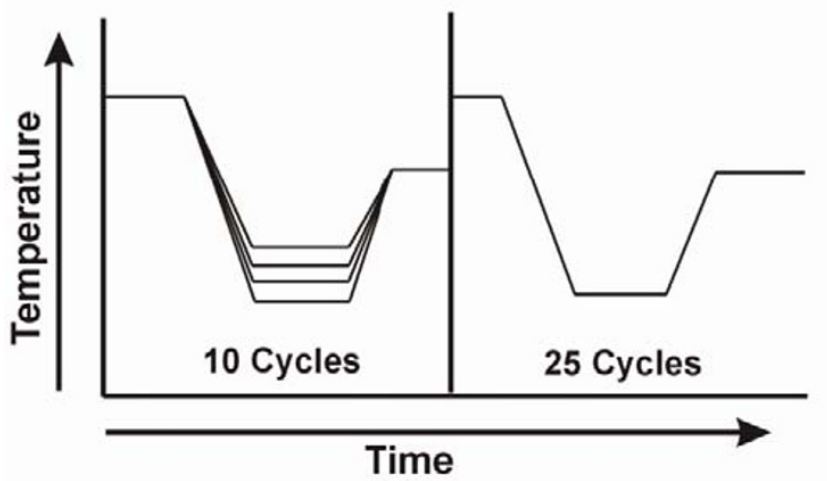

Time

\section{Secondary Amplification}

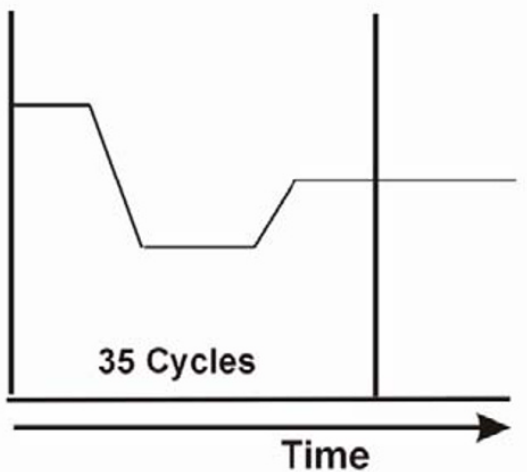

Time

B
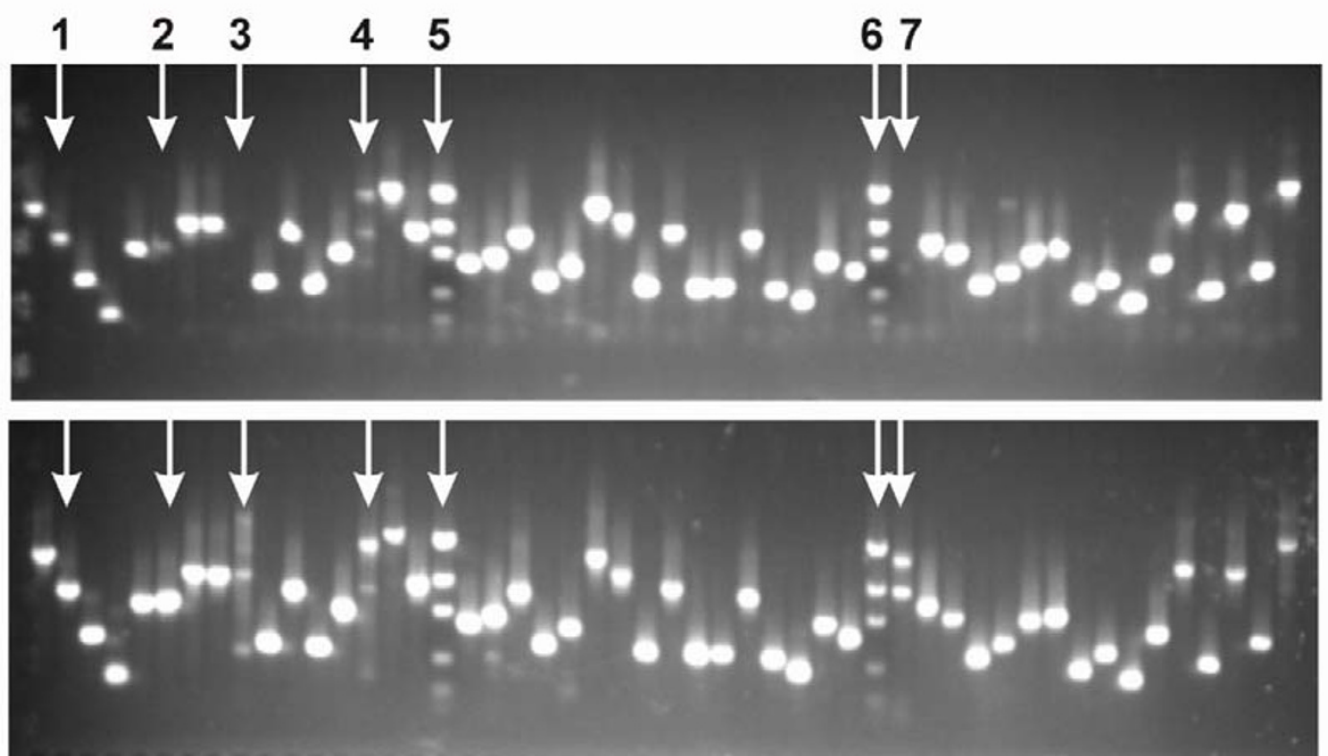

Figure 3

Thermal cycling conditions and resultant products from first and second rounds of amplification. Panel $A$ illustrates the thermal cycling conditions for the primary and secondary amplifications. During the first round amplification (Panel A, left side) with gene-specific chimeric primers, step-down thermal cycling PCR conditions involve decreasing the annealing temperature by $1^{\circ} \mathrm{C}$ per cycle beginning at $62^{\circ} \mathrm{C}$ for 10 cycles and the subsequent 24 cycles have a set annealing temperature of $52^{\circ} \mathrm{C}$. The graph on the right depicts the conditions for constant annealing temperature of $55^{\circ} \mathrm{C}$ for the second round amplification using a common set of adaptamers primers complementary to the entire set of first round products (Panel A, right side). Panel B illustrates one half (48 reactions) of the results from the primary (above) and secondary (below) amplification of one 96-well plate. Lanes 2 and 6 (arrows I and 2) illustrate the product 'leveling effect' on the yields of product due to the secondary amplification with adaptamer primers. Lanes 9, 14, and 35 (arrows 3, 4, and 7) illustrate missing or double products which are scored as bad and have new primers designed for subsequent use in another PCR run. Lanes 17 and 34 (under arrows 5 and 6 , respectively) contain molecular weight markers. 


\begin{abstract}
Hybridization of the microarray with sample representing the mRNA population is accomplished by synthesizing complementary DNA (cDNA) using reverse transcriptase. Microarray experiments in prokaryotic organisms cannot utilize the poly $(A)$ tails found in eukaryotic mRNA; thus, alternatives to the highly successful methods employed for generating fluorescent cDNA using oligo-dT to prime the reverse transcription labeling reaction have to be employed.

- cDNA synthesis Tests comparing random hexamers and random octamers gave essentially indistinguishable results. On the other hand, critical parameters for maximizing signal-to-noise were: I.) high level of incorporation of fluorescent dye by using a high ratio of amino allyl dUTP in the reverse transcription reaction and saturating amount of reactive dye during the coupling of activated dye; and 2 .) the use of two purification steps relying on independent physical separation principals applied to the test sample: first after cDNA synthesis and second, after the coupling of fluorescent dye. Direct chemical labeling of RNA, while attractive, did not allow as high signal-to-noise during our tests. Similarly, pilot experiments using pooled $3^{\prime}$ gene-specific oligos as cDNA primers did not give better results.

- Hybridization: While increases in signal-to-noise were associated with optimization of fluorescent sample production (above), a fairly wide range of standard microarray pre-hybridization and hybridization protocols were found to give comparable results. However, critical aspects of the described method were keeping the microarray slide warm during the addition of sample to the surface following pre-hybridization and ensuring that the slide remains hydrated prior to the final drying immediately before scanning.
\end{abstract}

tion. Nevertheless, the percentage of successful products after the first round synthesis appeared quite low, based on yield as visualized in the ethidium stained electrophoretic gels. Some lanes showed little to no product or multiple products after the first round amplification with the chimeric primers. However, these products generally resulted in successful amplification after their use as template in the second round amplification when the universal sequences introduced as overhangs of the chimeric primers during the first round amplification were used. Thus, the universal primers in the second round amplification provided the additional benefit of generating consistent yields across most of the genes (see Figure 3). Apparently, the amount of correct template produced by the $1^{\text {st }}$ round PCR, albeit often invisible during gel analysis, was usually sufficient to give high yields during the $2^{\text {nd }}$ round of amplification using the common adaptamer sequences. Thus $86 \%$ of the products were successfully amplified during our initial round of two-stage PCR. Primers for the $14 \%$ unsuccessful products were redesigned and synthesized, so that essentially all of the annotated genes were successfully amplified. Therefore, we conclude that this two-stage amplification strategy for the purpose of PCR amplifying multiple products for genome scale applications is highly successful, robust and efficient.

The use of adaptamer sequences with identical $\mathrm{T}_{\mathrm{m}}$ 's for the $2^{\text {nd }}$ round of amplification optimized the yields, despite different product lengths and different template concentrations (which were dependent on the yield from the first round reactions). The enzyme and thermocycling conditions were also optimized. The choice of Platinum Pfx (Invitrogen) as the polymerase was determined to be crucial as was its use in conjunction with the proprietary reaction enhancer solution supplied with the buffer. Tests with alternatives, including mixes of Taq and $P f u$, yielded less satisfactory results. All the images for the analysis of the PCR amplification are available at: http://microbiology.okstate.edu/faculty/burnap/index.html.

Organization and quality control were emphasized throughout production of the microarrays to ensure uniformity and accuracy. A semi-automated gel analysis procedure scored products on the basis of size and absence of multiplicity. All PCR products were documented by digital photography and the images quantitatively analyzed using Total Lab ${ }^{\text {тм }}$ Phoretics gel analysis software (Nonlinear Dynamics. Durham, North Carolina). This application was found to be most accurate, user-friendly, and efficiently handled dual tier gels. Furthermore, as with other packages, it allowed simple export of the numerical results to Excel spreadsheets. A database was developed to integrate information, including gene sequences, oligonucleotide design, PCR product length, etc. In addition, Excel macros were developed to transform the aforementioned information to produce lists for each plate, which were then used to track and identify the location of the arrayed elements under any condition, including the use of different array configurations. The scoring system, described in the Materials and Methods section, was set up to identify successful PCR amplified products.

DNA purification was simply and efficiently performed using filtration-type purification plates. Early issues with variation in printed spot morphology were resolved by pre-rinsing the filters: apparently this removes material acting as a surfactant and effects the spot morphology and/or drying characteristics. Alternatives such as ethanol or isopropanol precipitations were explored, but for the chosen PCR conditions, produced less reliable results and appeared to cause the co-precipitation of non-DNA material that interfered with downstream operations. The nature of this material remains undefined, although it may be due to constituents of the PCR reaction proprietary enhancer that is supplied with the Pfx polymerase. 


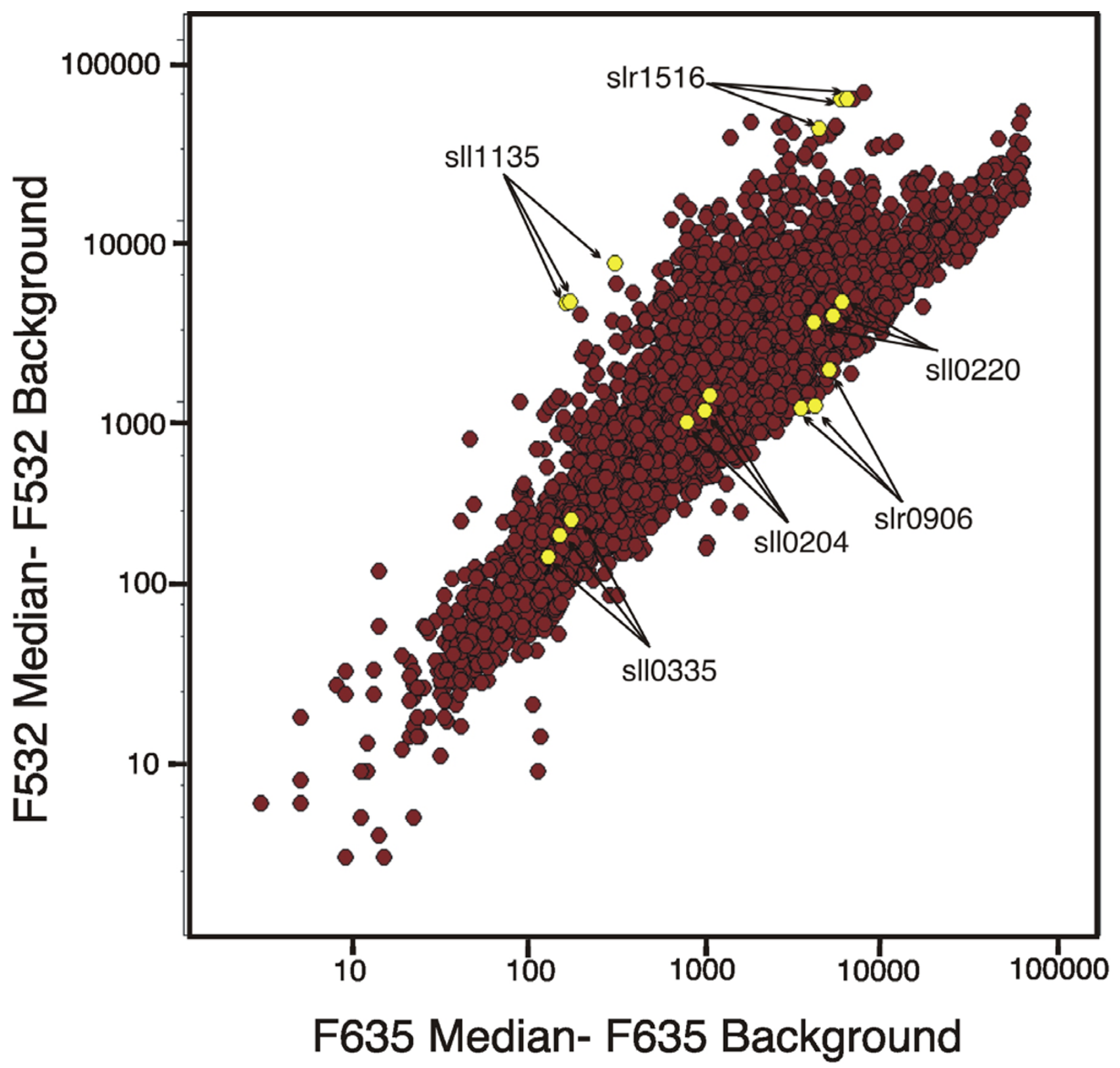

Figure 4

Scatter-plot of differential hybridization of fluorescently labeled cDNA from a 3-hour salt shock treated cell culture versus an untreated sample. Log phase cultures were subjected to an upshift in $\mathrm{NaCl}$ concentration from $\sim 25 \mathrm{mM}$ to $650 \mathrm{mM}$. Synechocystis is halotolerant and grows at concentrations up to approximately I.2 M NaCl. Fluorescently labeled (Cy-3) cDNA derived from total RNA extracted from cells exposed 3 hours to the higher salt concentration was co-hybridized with Cy-5labelled cDNA derived from the culture immediately prior to the upshift (control cells). The full genome Synechocystis sp. PCC 6803 high-density microarrays contain DNA features printed in triplicate on glass slides. The gene names according to original annotation are behind the arrows. As indicated with arrows, signals from the replicated elements exhibited similarity in the estimated expression ratio. Each data point corresponds to a different gene address on the microarray and each gene is replicated at three separate and spatially distant addresses. The $X$ and $Y$ axes correspond to the normalized fluorescence intensity of fluorescence-labeled cDNA of the control sample ( $Y$-axis, Cy-5, $532 \mathrm{~nm}$ fluorescence) and the $650 \mathrm{mM} \mathrm{NaCl}$ three hour time point (X-axis, Cy-3, $635 \mathrm{~nm}$ fluorescence). 
The concentrations of the purified DNA fragments were determined (Molecular Devices Spectramax Plus) and a Qiagen Bio-Robot 3000 was used to dilute the DNA samples to $500 \mathrm{ng} / \mu \mathrm{l}$ in $2 \mathrm{X}$ spotting solution. Tests showed that the combination of Superamine slides and MSP printing buffer solution from Telechem provided the best combination of spot morphology, retention of DNA after processing of slides and signal-to-noise ratio after hybridization. Alternately, Clontech type II slides in combination with the Telechem spotting buffer also gave good results in terms of printing and hybridization results. Tests with other buffer systems, e.g. 6X SSC and $50 \%$ DMSO, gave less satisfactory results under the specified printing conditions. The synthesis and hybridization of the fluorescently labeled cDNA derived from sample RNA is outlined in Table 2.

In order to generate uniform spot morphology and to maximize DNA concentration and consistency for each spot across the array, all products were printed at the same concentration. This was accomplished using the Qiagen Bio-robot $3000^{\mathrm{TM}}$ to resuspend each of the purified PCR products to the same concentration, based on the results of the Spectramax UV analysis. These products were then mixed with an equal volume of $2 \mathrm{X}$ MSP printing buffer from Telechem and two aliquots were transferred via the Bio-robot to separate printing plates. The use of this robotic transfer reduced the chance for human error, increased the rate of transfer (thus reducing the exposure of the products to desiccation), and increased the reproducibility of the transfer. Syto-61 staining was regularly used to maintain a high level of quality control during the printing process.

Several internal and external comparisons were analyzed to demonstrate the effective use of the arrays. Internally, the use of triplicate spotting of all array elements and distribution of the triplicate elements in different regions of the array allows the comparison of hybridization uniformity across the array, as depicted in Figure 4. Initially, we determined the effectiveness of printed slides by hybridization with total RNA from control and saltstressed cells. The results were compared with that of the published report from Kanesaki et al. [11]. Similar patterns of regulation of specific transcripts were observed and several examples of the differentially regulated genes are indicated in Figure 4. Qualitatively similar results using a direct RNA-dye coupling procedure can be achieved using the Micromax ${ }^{\mathrm{TM}}$ ASAP RNA Labeling Kit (Perkin Elmer Life Sciences, Inc. cat. No. MPS544) following the manufacturer's suggested protocol. While it is significantly quicker and requires less manipulation, the direct chemical labeling kit is more expensive, and produces a final RNA product which is less stable than the cDNA produced. Significantly direct labeling has thus far not provided as high a hybridization signal-to-noise ratio compared to the chemical coupling to cDNA approach.

Substantial effort was devoted to ensure spot uniformity, high signal-to-noise ratio, and good statistical reproducibility. We believe that we have met these objectives, and these arrays relate favorably to the best of current prokaryotic and eukaryotic arrays. The strengths of these Synechocystis arrays include: 1.) consistent and high DNA concentrations in each of over 11,000 spots per array; 2.) 3 replicates per probe per slide; and 3.) high signal-tonoise ratio. This last parameter is due both to the quality of the slides, the hybridization procedures that we utilized and the quality of the products printed. We have used these arrays to develop robust statistical tools for the analysis of the microarray data. The analysis involves an ANOVA model that makes excellent use of the technical replicates designed into each slide and a loop design (Singh, McIntyre and Sherman, unpublished results). The availability of large quantities of DNA, the ability to print many slides and the statistical tools will enable us to analyze transcriptional changes under many environmental conditions and for many mutants. The two-stage amplification procedure also provides full gene copies for techniques like PCR-fusion mutagensis. This will permit many comparisons among different conditions and should greatly facilitate functional genomics. In conclusion, the two-stage PCR amplification strategy detailed here is demonstrated to be highly useful and undoubtedly can be applied to other bacterial species.

\section{Competing interests}

None declared.

\section{Authors Contributions}

BLP, H-LW and RLB developed and optimized the PCR primer design strategy, BLP, H-LW, AS, HW, and LI performed the PCR amplifications; HLA, JK, and GR performed gel analysis and quality control, DP developed informatics, BLP, AS, MD, and DWG conducted the microarray printing, $\mathrm{BP}$, LAS, and RLB organized the project and prepared the manuscript.

\section{Acknowledgements}

The authors would like to acknowledge Dr. Prade, Dr. Cushman, Dr. Bonhert, and Dr. Stintzi for their advice and input. This work was supported by the National Science Foundation (to RLB and LAS) and the Department of Energy (to LAS) and by the Grula Fellowship to BP as part of his thesis work through the OSU Foundation.

\section{References}

I. Schena M, Shalon D, Davis RW and Brown PO: Quantitative monitoring of gene expression patterns with a complementary DNA microarray Science 1995, 270:467-470.

2. Spellman PT, Sherlock G, Zhang MQ, lyer VR, Anders K, Eisen MB, Brown PO, Botstein D and Futcher B: Comprehensive identification of cell cycle-regulated genes of the yeast 
Saccharomyces cerevisiae by microarray hybridization $\mathrm{Mol}$ Biol Cell 1998, 9:3273-3297.

3. lyer VR, Eisen MB, Ross DT, Schuler G, Moore T, Lee JCF, Trent JM, Staudt LM, Hudson J., Jr., Boguski MS, Lashkari D, Shalon D, Botstein $D$ and Brown PO: The transcriptional program in the response of human fibroblasts to serum Science 1999, 283:83-87.

4. White KP, Rifkin SA, Hurban P and Hogness DS: Microarray analysis of Drosophila development during metamorphosis Science 1999, 286:2179-2184.

5. Hihara Y, Kamei A, Kanehisa M, Kaplan A and lkeuchi M: DNA microarray analysis of cyanobacterial gene expression during acclimation to high light Plant Cell 200I, 13:793-806.

6. Richmond CS, Glasner JD, Mau R, Jin H and Blattner FR: Genomewide expression profiling in Escherichia coli K-I 2 Nucleic Acids Res 1999, 27:3821-3835.

7. Bryant DA: The Molecular Biology of Cyanobacteria The Netherlands, Kluwer Academic Publishers; 1994.

8. Kaneko T, Sato S, Kotani H, Tanaka A, Asamizu E, Nakmura Y, Miyajima N, Hirosawa M, Sugiura M, Sasamoto S, Kimura T, Hosouchi T, Matsuno A, Muraki A, Nakzaki N, Naruo K, Okumura S, Shimpo S, Takeuchi C, Wada T, Watanabe A, Yamada M, Yasuda M and Tabata $\mathrm{S}$ : Sequence analysis of the genome of the unicellular cyanobacterium Synechocystis sp. strain 6803. II. Sequence determination of the entire genome and assignment of potential protein-coding regions. DNA Research 1996, 3:109-136.

9. Williams JGK: Construction of specific mutations in Photosystem II photosynthetic reaction center by genetic engineering methods in Synechocystis 6803. Methods in Enzymology 1988, 167:766-778.

10. He Q, Dolganov N, Bjorkman O and Grossman AR: The high lightinducible polypeptides in Synechocystis PCC6803. Expression and function in high light $J$ Biol Chem 200I, 276:306-3 I4.

II. Kanesaki Y, Suzuki I, Allakhverdiev SI, Mikami K and Murata N: Salt stress and hyperosmotic stress regulate the expression of different sets of genes in Synechocystis sp. PCC 6803 Biochem Biophys Res Commun 2002, 290:339-348.

Publish with Bio Med Central and every scientist can read your work free of charge

"BioMed Central will be the most significant development for disseminating the results of biomedical research in our lifetime. "

Sir Paul Nurse, Cancer Research UK

Your research papers will be:

- available free of charge to the entire biomedical community

- peer reviewed and published immediately upon acceptance

- cited in PubMed and archived on PubMed Central

- yours - you keep the copyright
BioMedcentral 